\title{
Line in the application of modern clothing design
}

\author{
Zhu fang ${ }^{1, a}$ \\ ${ }^{1}$ Jiangxi Institute of Fashion Technology, Jiangxi, Nanchang, 330201 \\ a602357361@qq.com
}

Keywords: Line; Functional; Decorative; structural

\begin{abstract}
Line is an important part of the garment, it should not only meet the needs of the clothing modelling, but also to the clothing of people emotion, it affects different from each aspect $s$ aesthetic tendency of clothing, but also an important method of performance clothing modelling. In this paper, starting from the concept and types of clothing line, line are analyzed and the relationship between the clothing color, structure, this paper expounds the clothing line in the application of modern clothing.
\end{abstract}

\section{The introduction}

With the development of human society, the design of clothing also constantly change, from the style of oneness now evolved into various clothing modelling. In this process, the clothing line principle plays an important role. Line as the objective form of segmentation, has very important value in modern fashion design. It forms various, still can rise to segmentation and adornment effect, can change the deficiency of the human body posture, also can use line shape body beauty. Line with its own charm, is not only to satisfy the human body clothing comfort, at the same time also to the designer for clothing of emotions. Under this with diverse clothing fashion line design in the modern clothing has a certain significance.

\section{The classification of the clothing line}

Line refers to the important basis for clothing flat-fell seam formation province, has the role of provincial highway instead of clothing. But also the specific cash of formal dress, the realization of clothing from the surface into the important manifestation of the three-dimensional effect, so as to achieve beautiful clothes. According to the position classification on the clothes line in the clothing, can be divided into bust line and waist line respectively, shoulder line, brought the contour, the princess line and arc sleeve and armhole curve, etc. According to line linear feature points, can be divided into spiral line, such as straight line and curve line. According to the direction of line shape classification, can be divided into vertical line, radial line, horizontal line and diagonal line, etc.

\section{Line relationship with the whole of garment}

Clothing all integrity is the root of the art design, a tiny part of the line as the inside of the garment must follow the rules in line with the design of garments' integral modelling. The following respectively from the line and the clothing color, style, in-depth understanding of the relationship between the three.

Line and the relationship of clothing color. In human visual perception, the clothing color is the fastest information, the visual impact is the biggest, the most attractive, but the clothing color is dependent, it can't exist independently, that is to say, no shape, no color, and line just can give colour modelling. The same colour different modelling may convey emotions may be completely different. Color is improved line, line or colour, they are emotional characteristics, the combination of line and color effective use, can make the garment has a certain emotional atmosphere. If the body is the true embodiment of the clothing line design, the color is improved shape clothing modelling, curvaceous further reflect the human body, so be it clothing line or clothing color is shaping the posture of human body. Line can change its shape to show through clothing, and garment colour can through his lightness and strengthen position in the clothing to clothing. Clothing line and colour combination, the clothing color is the strengthening of the tightened rules 
on the vision. Stylist to highlight a woman's curvaceous, took the princess line segmentation and live on joint segmentation, make clothing and human body regardless of from the front or side got perfect combination, manifests the woman graceful posture. But curvaceous line sometimes cannot fully reflect the human body, can reflect by different lightness of clothing color and make up the defects of human body. Correct and reasonable use of clothing line and supplement each other's complementary relationship between clothing color, is the concept of modern designer shapes, make clothing line more fully expressed in clothing.

Line's relationship with garment structure. Line as one of the main structure of the internal design clothing, plays a very important role, both to meet the requirements of designers to consider to the difficulty of the craft that make, its segmentation outline beauty outside pay more attention to reflect dress, that is to say it in a certain degree decides the performance of the clothing external contour. Regardless of clothing styles are made in what kind of method, how the complex internal structure, give a person the visual effect is composed of one dimensional boundary two-dimensional spatial impression. Clothing styles to the person's vision is very important, style clothing line made is inseparable from the support, because the line determines the spatial hierarchy of clothing and the human body, of the intimate relationship.

Usually dress design, are clothing styles to decide the design of the line, the line design in style and clothing styles, if the profile design is simple and straight, so internal line should be concise, and easy, if the profile is sleek style, full, so is it internal line is coordinately, smooth, so that it can give a person the feeling is harmonious. But on the other hand, sometimes in order to design requirements, after first to design the internal structure of line, and to determine the design profile. Style design to start or internal structure design, should pay attention to the internal line and design, profile form is unified. In women's clothing, for example, the princess line segmentation, can reflect waist, profile, can take on the characteristics of $\mathrm{X}$, the vertical separation and horizontal segmentation can reflect comfortable profile, presents the characteristics of the H. Clothing line as a small part in the clothing design, it and clothing color, fabric, clothing design is interdependence, mutual restrict, so designers in the creation of clothing, should grasp well the relations between and among them.

\section{Line in the clothing design of use}

In the clothing design, designers use line to complete the shaping of human nature, and then use line to convey the designers' understanding of fashion design, called functional partition. Can pass line under the different causes, from the three aspects are discussed.

The use of functional partition. The body's natural form. Functional line mainly is to build the body's natural shape, through the split pieces of clothes, such as thoracic lumbar dispersion, etc., by the amount transferred to the line, then the body form a good show. So the main purpose of the functional partition, it is good to show the body's natural form. In the $1870 \mathrm{~s}$, Britain's famous designer Charles, the first to put forward the princess line line, as shown in figure 1 . This kind of segmentation, on the vision to people can well reflect the curve of human body, better performance of the chest, the difference in value between waist circumference and hip circumference, and waist, and the effect of the protruding buttocks, fully show the body $\mathrm{S}$ shape beauty.

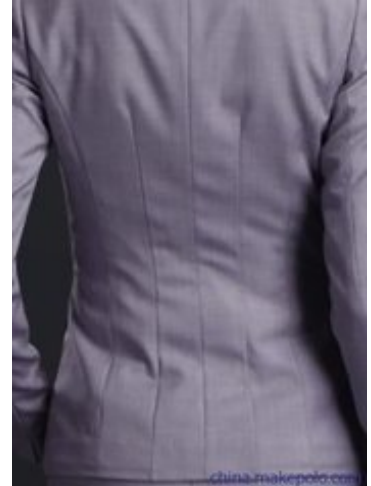

Fig.1 The princess line line
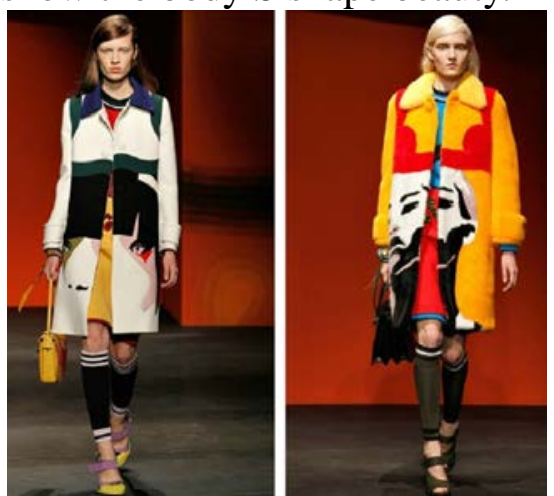

Fig. 2 Wears outside underwear clothing 
Clothing in vitro modelling design. Clothing modelling of carrier is a person, so the designers in the clothing design, be sure to people according to, but also by the structure of human body's own constraints. The human body and clothing yes relationship, not only the designers to design clothing, clothing modelling is not entirely dependent on human body, and according to the different designers design concept to design. This design is in fact in vitro clothing design, costume design is used between clothing and human body in vitro to zoom in and out the amount of space design, lead to changes in clothing silhouette. In the process, meet the designer's design concept in vitro, naturally formed many functional partition. In modern fashion design, with fashion designers different views of beauty, but also pay attention to the human body in natural form on the basis of the importance of beauty to the human body, and then through the study of the exaggerated modelling design of clothing a local to embody the idea of designers. , no matter how designers design is inseparable from the line in the flexible use of modern clothing. So the line in modern fashion design have this role.

The use of decorative divider. Decorative line is to meet the functional of the human body at the same time, in order to decorate, show the human body and clothing, and a line art effect on the vision. So, adornment sex is not the biggest difference between line and functional line of clothing functional role, but meet people's visual adornment effect. In the last century $20 \mathrm{~s}$, due to the outbreak of the first world war, changed the aesthetic of human body. In order to adapt to the war, most women out of the boudoir, step into society, has been wide waist straight women's clothing. During this period, the clothing is also follow change, appeared a lot of straight line, waist contraction, the waist, made a has the meaning of modern clothing. Silvio resistance works is the typical representative works of this period, the line is essentially horizontal, vertical line and broken line, decisive embodies the man resolute, determination of emotional characteristics, therefore, in the $20 \mathrm{~s}$ clothing line is essentially a straight line. Wears outside underwear line of "fashion" concept is communicated in the last century, by "the mother of punk" Vivian Westwood proposed the concept of a "" wears outside underwear, good embodies the function of decorative divider. Most designers not only accepted this kind of design concept, but also on the basis of the evolution of the different design style. Earlier years, many designers use clothes outside in the idea of using the shape of the hook out of the underwear has a certain texture profile, as shown in figure 2 . Thus it can be seen that the purpose of the line is not only in order to meet the clothing stereo modelling, and is to meet the visual demand and fashion concept, for the purpose.

The use of structural line. Structural functional line is decorative combination of line and functional partition, it should not only meet the functional line designed to meet the decorative line design. Compared with functional partition and decorative line, structural line difficulty is bigger, because it is meet the designer's aesthetic modelling design should also consider process implementation. So, structural line is to realize the clothing aesthetic and functional forms. Functional line, therefore, is the foundation of clothing aesthetic, decorative divider is required, the two can combine good use, is the modern designers lifelong study, according to their own creative purposes to consider the use of line, has become one of indispensable energy every designer.

\section{Conclusion}

Clothing line as one of the important means of modern fashion design, plays a very important role, not only to meet the needs of the clothing modelling, and people to the clothing of emotion expression, is an essential part of costume designer design method. Line design holds an important place in modern clothing design, the use of the line to become today's designers show a form of self unique style, and explore a new development direction for modern fashion design.

\section{Reference}

[1] Chen bin. Line application in knitting clothing design [J] Shanghai textile science and technology, 2011 (9).

[2] Ruochun Hong. No line in the application of clothing design [J] art science and technology, 2014 (3). 
[3] xuewei Wang. Analyses the application of rules in the clothing structure design [J] wit, 2011 (29).

[4] Wang zhong. Introduction to line in women's clothing design [J] the application of information science and technology, 2013 (5). 